\title{
NORUS
}

ISSN: $2318-1966$

v. 4, n. 6

jul - dez 2016

Dossiê

\section{A REBELIÃO DO VIVIDO: HENRI LEFEBVRE NO CENTRO DE SALVADOR}

Urpi Montoya Uriarte ${ }^{1}$

Prof $^{a}$ Adjunta do Departamento de Antropologia da Universidade Federal da Bahia (UFBA)

\begin{abstract}
RESUMO
Este artigo pretende trazer Henri Lefebvre para o centro de Salvador: usar suas ideias e categorias para interpretar alguns discursos e cenas na capital baiana, demonstrando como o que ele chamou de direito à cidade está sendo exigido hoje no Pelourinho e como o que ele denominou de a rebelião do vivido está acontecendo em espaços centrais, tais como a Avenida Sete de Setembro. O material empírico que este artigo analisa à luz das ideias e categorias lefebvrianas são um documento da Associação de Moradores e Amigos do Centro Histórico (AMACH) e o cotidiano de um vendedor de castanhas e camarão seco na Rua do Forte.
\end{abstract}

Palavras-Chave: Direito à cidade; Salvador; Henri Lefebvre.

\section{THE REBELLION OF LIVED HENRI LEFEBVRE IN THE CENTRE OF SALVADOR-BA}

\begin{abstract}
This article aims to bring Henri Lefebvre for the Centre of Salvador: use his ideas and categories to understand a discourse and a scene in heart of the capital of Bahia, demonstrating how what he called the right to the city is being demanded today in Pelourinho and what he called the rebellion of lived is happening in central spaces such as the Avenida Sete de Setembro. The empirical material that this article examines in the light of lefebvrian's ideas and categories are a document of Association of Residents and Friends of the Historic Centre (AMACH) and the daily life of a seller of chestnuts and dried shrimp in the Rua do Forte.
\end{abstract}

Keywords: Right to the city; Salvador; Henri Lefebvre.

\section{Introdução}

Este artigo pretende trazer Henri Lefebvre para o centro de Salvador: usar suas ideias e categorias para entender o centro da capital baiana, demonstrar como o que ele chamou de direito à cidade está sendo exigido hoje no Pelourinho e como o que ele denominou de a

\footnotetext{
${ }^{1}$ Antropóloga. Doutora em História social pela USP (1997).
} 
NORUS - v4, n.6, jul - dez 2016.

rebelião do vivido está acontecendo em espaços centrais, tais como a Avenida Sete de Setembro.

É verdade que trazer Henri Lefebvre para o centro de Salvador é tarefa que extrapola um curto e modesto artigo. Em primeiro lugar, porque trazemos apenas um Lefebvre, aquele que pensou a cidade (tema que ocupou suas preocupações no final dos anos 1960 e inícios dos anos 1970), referindo-nos principalmente a duas das seis obras desse período ${ }^{2}, O$ direito à cidade e A revolução urbana, deixando para outro espaço (e tempo) - de maior envergadura o trabalho que condensa suas reflexões sobre esta temática, A produção do espaço. Em segundo lugar, porque não falaremos do todo o centro antigo de Salvador - espaço bastante abrangente -, mas apenas de dois locais onde temos realizado trabalho de campo ao longo dos últimos anos, o Pelourinho e a Avenida Sete $^{3}$.

Lefebvre se refere à rebelião do vivido no final do livro A revolução urbana (p.166) para falar da importância do cotidiano e da práxis como condições e arenas essenciais para enfrentar as razões ditas técnicas, a suposta racionalidade, enfim, o espaço abstrato, noção bastante trabalhada em seu livro A produção do espaço (1974). Por espaço abstrato, Lefebvre entendia aquele espaço do capitalismo e do neo-capitalismo, onde imperavam as mercadorias, onde o concebido se impunha sobre o vivido, um espaço que tendia à homogeneidade pelo peso da racionalidade instrumental em sua produção, enfim, um espaço onde primavam os pactos de não-agressão, as distâncias respeitosas, o consenso e, no entanto, a violência permanecia latente. O império e imposição do concebido só poderia ser enfrentado pela rebelião do vivido. No caso do centro de Salvador, reconhecemos esta rebelião nas queixas e propostas da Associação de Moradores e Amigos do Centro Histórico (AMACH) em relação ao espaço que desejam para si e nos espaços praticados pelos vendedores informais de rua.

Henri Lefebvre foi um filósofo que escreveu sobre Hegel, Marx, Nietzsche e Lênin. Foi um dos introdutores do marxismo na França, autor de um livro que foi um sucesso de vendas, O marxismo (na coleção “Que sais-je?”, 1948), com mais de 23 edições na França. Mas não são essas as obras que fazem de Lefebvre um autor conhecido nos dias de hoje. Ele é hoje reconhecido pelo que produziu em sua etapa de reflexão sobre a cidade e o espaço, no período compreendido entre 1967 e 1974 . Este reconhecimento foi particularmente amplo nos países anglo-saxões, propiciado por autores como Perry Anderson e, sobretudo, o influente

\footnotetext{
${ }^{2}$ O direito à cidade (1968), Do rural ao urbano (1970), A revolução urbana (1970), O pensamento marxista e a cidade (1972), Espaço e política (O direito à cidade II) (1973), A produção do espaço (1974).

${ }^{3}$ Para trabalhos sobre o Pelourinho após a intervenção de 1991 e sobre a Avenida Sete, remetemos o leitor a Montoya Uriarte (2012a, 2012b, 2010) e Carvalho Filho; Montoya Uriarte (2012a, 2012b), respectivamente.
} 


\section{A rebelião do vivido: Henri Lefebvre no centro de Salvador.}

David Harvey ${ }^{4}$. Mesmo assim, dentre os autores franceses, certamente Lefebvre não é o mais lido, ficando muito aquém de Jean-Paul Sartre, dos estruturalistas e, mais recentemente, de Michel Foucault, Jacques Derrida e Gilles Deleuze.

No entanto, nós escolhemos Lefebvre para guiar a nossa leitura de discursos e cenas do centro de Salvador. A principal razão não radica na riqueza de sua interpretação humanista da realidade, ou a riqueza de suas categorias, ou o seu método regressivo-progressivo, elogiado inclusive por Sartre (a quem dirigiu duras críticas). O que mais admiramos na obra de Lefebvre é sua confiança no possível, que não deve confundir-se com um simples otimismo. Lefebvre era um visionário, um homem de possibilidades, interessado em descobrir as virtualidades contidas no presente. A sua foi uma tentativa, como ele mesmo escreveu, de “abrir o pensamento e a ação na direção de possibilidades que mostrem novos horizontes e caminhos" (LEFEBVRE, 1969, p. 7). Nenhuma conformidade com o real e, sim, pelo contrário, um pensamento crítico e utópico. Referindo-se à crítica de esquerda, escreveu:

é aquela que tenta abrir a via do possível, explorar e balizar um terreno que não seja simplesmente aquele do "real", do realizado, ocupado pelas forças econômicas, sociais e políticas existentes. É, portanto, uma crítica u-tópica, pois toma distância em relação ao real, sem, por isso, perdê-lo de vista (LEFEBVRE, 2000, p. 20).

O chamado "romantismo revolucionário" de Lefebvre repousa nesse utopismo, que não é fuga ou evasão, mas imaginação do possível. No meio de generalizado desencanto que vivemos nas últimas décadas, Lefebvre nos traz um sopro de energia, emoção e imaginação para recusar a atitude que políticos e capitalistas querem propagar: a de que não há alternativas, a de que toda utopia é ingenuidade ou perda de tempo. Mas nada mais longe do utopismo de Lefebvre do que sonhos ou fantasias. Ele acreditava que a imaginação só podia emergir do que já existe, conclamando para que as virtualidades do presente sejam vistas, para que sejam captadas as possibilidades alternativas contidas nas práticas efetivas.

Não é, pois, coincidência que a temática urbana aparecesse em Lefebvre nas décadas de 1960 e 1970: um período particularmente intenso de luta urbana, com o famoso Maio de 68 e os múltiplos movimentos sociais lutando por diversos direitos em todas as cidades do chamado Terceiro Mundo: “A América encontra-se envolvida na guerrilha urbana”, escrevia

\footnotetext{
${ }^{4} \mathrm{Na}$ França, pelo contrário, esta produção ficou restrita a um pequeno círculo de urbanistas. Calcula-se em mais de cinquenta as obras sobre Lefebvre em inglês, alemão e espanhol. Nos últimos dez anos, a tradução inglesa de A produção do espaço vendeu mais de trinta mil exemplares. No Brasil, dez obras sobre Lefebvre apareceram desde 2001. Já os franceses não acompanham este ritmo. Uma das razões esboçadas por Remi Hess, no prefácio ao livro de Hugues Lethierry (2009), é o grande número de inimigos que ele fez ao longo dos noventa anos de sua vida (1901-1991). Na França, a apreciação do homem ("enfant terrible") interfere até hoje na apreciação da obra. Lethierry menciona também a sua escrita, rápida, com poucos subtítulos, sem resumos, emotiva (cheia de pontos de exclamação), de um estilo oral, preocupada em lançar sementes mais do que em sua germinação.
} 
NORUS - v4, n.6, jul - dez 2016.

em A revolução urbana (2002, p. 133), referindo-se às ações dos guetos norte-americanos e das favelas latino-americanas. Vislumbrava o início de um novo período, o das revoluções urbanas:

Continentes inteiros passam das formas anteriores de ação revolucionária à guerrilha urbana, aos objetivos políticos concernentes à vida e à organização urbanas (sem poder omitir nem resolver, por isso, os problemas da organização industrial e da agricultura que se superpõem). Começa o período das revoluções urbanas (LEFEBVRE, 2002, p. 49).

Assim, foi a realidade que fez emergir a temática urbana no filósofo e pensador marxista. Foram as virtualidades contidas nela que o levaram a se perguntar pelas organizações e suas potencialidades. Seus escritos sobre a temática foram pensados como uma contribuição para tais movimentos, já que o socialismo de Estado nada tinha pensado ou inovado em relação às cidades, a vida urbana e o fazer municipal. Mas não deixou nenhum programa, nenhuma estratégia, nenhum novo espaço modelado, pois nada fechado cabia em seu utopismo. É esta a leitura (e a crítica) de Harvey:

Lefebvre é resolutamente antagônico ao utopismo da forma espacial tradicional
justamente por causa do autoritarismo fechado deste. Ele elabora uma devastadora
crítica de concepçôes cartesianas, do absolutismo político que advém de concepções
absolutas do espaço, das opressões que se abatem sobre o mundo devido a uma
espacialidade racionalizada, burocratizada, definida tecnocrática e e
capitalisticamente. Para ele, a produção do espaço tem de permanecer uma
possibilidade interminavelmente aberta. O efeito, infelizmente, é deixar
frustrantemente indefinidos os espaços reais de alguma alternativa (HARVEY,
2004, p. 240).

Esta aposta pelo que Harvey chama de "interminavelmente aberto" condiz com o que nos parece ser a preocupação central de Lefebvre: a plenitude do ser humano. Era indispensável, para ele, pensar numa casa e numa cidade feitas pelo homem e para o homem, nas quais a integridade e a plenitude do homem fossem colocadas em primeiro plano. Em $A$ revolução urbana, esta preocupação antropológica aparece de forma bastante clara:

O ser humano tem "necessidade" de acumular e de esquecer; tem necessidade simultânea ou sucessivamente de segurança e aventura, de sociabilidade e de solidão, de satisfações e de insatisfações, de desequilíbrio e de equilíbrio, de descoberta e de criação, de trabalho e de jogo, de palavra e de silêncio. A casa, a morada, a residência e o apartamento, a vizinhança, o bairro, a cidade, a aglomeração, satisfizeram, ainda satisfazem, ou não satisfazem mais a alguns desses apelos (LEFEBVRE, 2000, p. 72).

Eis o porquê do seu marxismo ter sido denominado, também, de "humanista". É este humanismo que o fez polemizar com outro intérprete de Karl Marx, o estruturalista Louis Althusser, a quem criticava precisamente o esquecimento da práxis. Apesar de ser um homem de partido (membro do Partido Comunista Francês durante trinta anos, de 1928 a 1958), Lefebvre nunca foi um marxista ortodoxo, fechado no dogma, conformado com interpretações 


\section{A rebelião do vivido: Henri Lefebvre no centro de Salvador.}

prontas. Do marxismo, bebeu principalmente duas ideias: a teoria da alienação e a crítica do Estado (DEULCEUX; HESS, 2009). Mas o seu marxismo propunha ir mais longe que Marx, afirmando, por exemplo, que o pensador alemão não tinha colocado em questão o problema urbano e que o único problema estudado tinha sido o de moradia, refletido por Friedrich Engels. Afirmações como estas propagaram a sua denominação de revisionista e indisciplinado. Daí porque, no prefácio à edição brasileira de A revolução urbana, Sérgio Martins se refere à "ousadia lefebvriana" que teria lhe custado "a periferia dos panteões institucionais", a sua "periferização". No entanto, foi precisamente desde a periferia onde foi colocado que lhe foi possível abordar aspectos da realidade tidos como secundários para os marxistas: a vida cotidiana, a produção do espaço, a conjuntura.

Lefebvre foi um homem emotivo, amante da festa, da vida cotidiana, das mulheres, dos momentos. À estrutura, ele opôs a conjuntura. "Este paradigma do conjuntural, Lefebvre o partilhou com os situacionistas, notadamente. Trata-se de uma paixão pelo momento, onde as estruturas não conseguem dominar seus próprios elementos" (DEULCEUX, HESS, 2009, p. 73). Para ele, a noção de estrutura devia ser complementada, dialeticamente, com a de conjuntura: "Temos falado muito da estrutura. O que me interessa é a relação da estrutura com a conjuntura. A conjuntura, isto é, o conjunto de circunstâncias, causas e razões exteriores à estrutura que podem modificá-la, transtorná-la, trazer uma outra estrutura" (apud DEULCEUX; HESS, 2009, p. 93). Essa atenção ao momento, à conjuntura, ao que pode ser modificado, explica a intensidade de sua produção no momento das revoluções urbanas. $\mathrm{O}$ tema da revolução, aliás, foi anterior e posterior a este período. Em que momentos a revolução se torna possível? Quem pode e quem deve liderar a revolução? Que lições podem ser tiradas das experiências revolucionárias passadas? Foi com esses interesses que Lefebvre se voltou para o estudo da Comuna de Paris, resultando no livro A proclamação da Comuna (1965), no qual começa a desenvolver a ideia segundo a qual a revolução é uma festa. Festa e ludicidade seriam retomadas em $O$ direito à cidade.

Após concluir o seu A produção do espaço (1974), Lefebvre se aposenta. De taxista na década de 1920, ele chegou à universidade, com 61 anos de idade, tardiamente, devido à sua militância comunista, e ficou pouco tempo, lamentavelmente. Depois da aposentadoria, já longe das pesquisas urbanas empíricas dos alunos e colegas ${ }^{5}$ e do espírito que formaria a

\footnotetext{
${ }^{5}$ A sociologia urbana de Lefebvre se desenvolveu na década de 1960, em Strasbourg, primeiro e, depois, em Nanterre. Data dessa época também a sua aproximação com os situacionistas e sua intensa amizade com Guy Débord. No Instituto de Sociologia Urbana (ISU) coordenou os trabalhos de pesquisadores como Nicole Haumont e Henri Raymond, estudiosos dos grandes conjuntos habitacionais e das casas (pavillonaires), que
} 
NORUS - v4, n.6, jul - dez 2016.

Internacional Situacionista e o Maio de 68, Lefebvre volta a se reaproximar da filosofia e do Partido Comunista (embora sem se readmitir), e a questão do marxismo volta a tomar conta de suas preocupações (LETHIERRY, 2009, p. 209).

\section{O direito à cidade no pelourinho}

O direito à cidade é uma expressão bastante conhecida hoje em dia, e precisamente por isso a ideia contida na expressão parece prescindir de longas apresentações. Com efeito, em diversos países, a expressão cunhada por Lefebvre tem se tornado cada vez mais usada, tornando-se inclusive slogan de vários movimentos que nunca ouviram falar em Lefebvre (HARVEY, 2011). Mas é necessário não confundir o direito à cidade com o direito a alguma ou algumas coisas, como a rua asfaltada, um teto, eletricidade ou água encanada. O que este direito coloca em questão não são coisas, mas algo mais vago, porém, essencial: a vida cotidiana na cidade, uma cidade feita de satisfação e prazer, de encontros, ludicidade e imprevisibilidade; o direito a habitá-la, a praticá-la, a moldá-la em função dos valores de uso, o direito à obra. Assim, a meu ver, o que Lefebvre chamou de o direito à cidade não é o direito a uma casa, ou uma praça (isto é, espaços), mas o direito ao valor de uso primar sobre o valor de troca (isto é, os usos dos espaços).

Em $O$ direito à cidade, o autor propôs uma distinção conceitual entre habitar e habitat. Habitar é participar, se apropriar: “Até então, 'habitar' era participar de uma vida social, de uma comunidade, de uma aldeia ou cidade. A vida urbana detinha, entre outras, essa qualidade, esse atributo. Ela deixava habitar, permitia que os citadinos-cidadãos habitassem" (LEFEBVRE, 1969, p. 21). Habitar é uma prática ao mesmo tempo funcional, multifuncional, transfuncional (LEFEBVRE, 2000). Já o habitat é uma imposição, uma "soma de coações", algo "instaurado pelo alto"; um atentado à diversidade de maneiras de viver; uma redução do ser humano a algumas de suas funções elementares (comer, dormir, reproduzir):

Os pavilhões permitem variantes, interpretações particulares ou individuais do
habitar. Uma espécie de plasticidade permitia modificações, apropriações. O espaço
dos pavilhões - recinto, jardins, cantos diversos e disponíveis - deixava ao habitar
uma margem de iniciativa e de liberdade, limitada mas real. A racionalidade estatal
vai até o fim. No novo conjunto instaura-se o habitat em estado puro, soma de
coações. O maior conjunto realiza o conceito de habitar, diriam certos filósofos, ao
excluir o habitar: a plasticidade do espaço, a modelagem desse espaço, a apropriação
pelos grupos e indivíduos de suas condições de existência. É também a
quotidianeidade completa, funções prescrições, emprego rígido do tempo que se
inscreve e se significa nesse habitat (LEFEBVRE, 1969, p. 23). desenvolvem trabalhos na área até hoje. Entre 1962 e 1973, se envolveu com 96 teses universitárias (DEULCEUX; HESS, 2009, p. 25). 
"O habitat foi instaurado pelo alto: aplicação de um espaço global homogêneo e quantitativo obrigando o 'vivido' a encerrar-se em caixas, gaiolas, ou 'máquinas de habitar'” (LEFEBVRE, 2000, p. 81), fazendo com que poesia essencial do habitar se perdesse, deixando o ser humano numa profunda miséria existencial. O nível do habitar "é o essencial, o fundamento, o sentido" de qualquer reforma urbana e qualquer pensamento radical, porque "põe em primeiro plano os problemas relativos aos lugares concretos onde se exercem as relações sociais" (LEFEBVRE, 2000, p. 97).

$\mathrm{O}$ direito à cidade, o habitar e o valor de uso perpassam as queixas e reivindicações da AMACH. Trago para esta discussão um documento em particular, curto, mas significativo do quanto Lefebvre soube transformar em categorias o que os movimentos sociais urbanos expressam em outras palavras, mais simples, porém com o mesmo significado (AMACH, $2008^{6}$ ). A AMACH é uma organização que vem tendo uma atuação muito importante no Pelourinho desde 2001. A "recuperação" do Pelourinho, pensada e coordenada pelo Estado da Bahia, no governo de Antônio Carlos Magalhães, e cujas obras se iniciaram em 1993, provocou a indignação de certos setores, em particular dos movimentos culturais e alguns intelectuais. No entanto, até 2001, os moradores do Pelourinho reformado pouco se fizeram sentir e ouvir, silenciados que foram pelas parcas indenizações que receberam e pelo escasso interesse da sociedade civil em ouvi-los. A AMACH é, nesse contexto, uma das poucas respostas à "recuperação" que, qual trator, passava por cima de moradores pobres da área, expulsando-os para criar um novo espaço central, destinado a outro tipo de usuários e usos ${ }^{7}$. É importante frisar que esta organização contou com o apoio de indivíduos e instituições, dentre as quais destaco a assessoria da área urbana do Centro de Estudos e Ação Social (CEAS).

Após uma luta árdua iniciada em 2001, a AMACH conseguiu, em $1^{\circ}$ de junho de 2005, a assinatura do Termo de Ajustamento de Conduta (TAC) pelo promotor de justiça e representantes do Estado da Bahia e da Companhia de Desenvolvimento da Região Metropolitana de Salvador (CONDER) ${ }^{8}$. O TAC garantiu a permanência de 103 famílias na $7^{\text {a }}$ etapa de revitalização do Centro Histórico de Salvador (CHS). A segunda cláusula desse acordo conferia um lugar destacado à participação da comunidade no projeto das novas moradias e dos espaços públicos, em consonância com a legislação brasileira que garante a

\footnotetext{
${ }^{6}$ Agradeço a José Maurício Daltro Bittencourt, do Centro de Estudos e Ação Social (CEAS), por ter me fornecido este documento.

${ }^{7}$ Em Montoya Uriarte (2003) refiro-me em detalhes a este processo de expulsão.

${ }^{8}$ A luta da AMACH foi narrada e descrita em Montoya Uriarte (2012a).
} 
participação da população envolvida em qualquer projeto habitacional. Com efeito, o Estatuto da Cidade (lei n. 10.257, de 10 de julho de 2001), que regulamenta os artigos 182 e 183 da Constituição Federal de 1988, prevê a gestão participativa dos habitantes, isto é, a participação da população no que diz respeito a seu habitat.

Assim, a referida cláusula afirmava: “O projeto de recuperação da $7^{\mathrm{a}}$ etapa do Centro Histórico de Salvador será objeto de discussão com a comunidade, visando a compatibilização das unidades habitacionais à composição das famílias, definindo-se os equipamentos coletivos e programas de ação" (apud AMACH, 2008, p. 4). Contudo, os órgãos responsáveis pelo projeto e implementação da $7^{\mathrm{a}}$ etapa, nesse momento - o Instituto do Patrimônio Artístico e Cultural da Bahia (IPAC) e a CONDER -, nunca apresentaram e muito menos discutiram tais projetos com a comunidade. O documento da AMACH assim o lamenta: "As 103 famílias é que tiveram ou terão que se adaptar à composição dos novos imóveis: novo endereço, novos vizinhos, novas plantas baixas" (AMACH, 2008, p. 5). Prometeram-se apenas apartamentos com menos de $50 \mathrm{~m}^{2}$, confundindo claramente o que Lefebvre distinguia tão bem: habitar e habitat.

A participação, apesar de constar no papel, não se verifica na prática política cotidiana dos setores que governam e dirigem as cidades. Em sua visita ao Brasil, no ano de 2004, o relator especial das Nações Unidas para a Moradia Adequada, Sr. Miloon Khotari, informou:

\footnotetext{
Durante a minha visita eu testemunhei uma contradição com relação aos processos participativos. Ainda que a democracia e a sociedade civil sejam fortes e, ainda mais, que o governo federal em particular tente assegurar a participação no processo de decisão aliado à realização de conferências nacionais, existe uma lacuna de participação real no planejamento e desenvolvimento de planos e alocações de recursos a nível local. O Estatuto da Cidade se constitui em um instrumento para a elaboração participativa no desenvolvimento de planos e alocação de recursos e prevê mecanismos inovadores relativos a: zonas especiais de interesse social, estudos de impacto de vizinhança, segurança da posse e regularização fundiária. No entanto, de acordo com depoimentos dados sobre o desenvolvimento do Plano Diretor de cidades como Fortaleza e Salvador, onde importantes recursos são gerados a partir do turismo, o acesso a tal participação e desenvolvimento do planejamento urbano tem sido negado a movimentos da sociedade civil, apesar de, no caso de Salvador, existir uma ordem judicial em contrário. Este caso ilustra a necessidade de educação e treinamento da sociedade civil e do governo local para assegurar a implementação do Estatuto da Cidade (KHOTARI, 2004, p. 6).
}

Além de se adaptar à composição dos imóveis pensados por outros para eles, as famílias cuja permanência no Pelourinho foi garantida pelo TAC veem-se impedidas de pensar conjuntamente os espaços coletivos do bairro. Elas reivindicam a necessidade de equipamentos comunitários no local, no entanto, o IPAC e a CONDER preferiram destinar um grande espaço livre para instalar um estacionamento. Alegando que já havia três 


\section{A rebelião do vivido: Henri Lefebvre no centro de Salvador.}

estacionamentos no CHS e que sobravam vagas nos três turnos, a $\mathrm{AMACH}$ entende "que o melhor é transformar o interior do quarteirão $28 \mathrm{~S}$, para o qual projetaram mais um estacionamento sem nos consultar, em um equipamento comunitário eficiente, moderno e motivador da revitalização das áreas adjacentes, contendo creche, espaço de lazer e de geração de emprego e renda" (AMACH, 2008, p. 6). Por outro lado, a AMACH rejeita a imposição de uma sede-creche que não foi discutida com eles e, portanto, apresenta-se inadequada fisicamente:

Por não ter sido gerado com a comunidade, o projeto da sede-creche não tem propósito. Cria espaços para atividades que nem sequer foram previamente estudadas. A creche, com recepção no subsolo, duas salas e um berçário de 14,99 metros quadrados (caberiam 4 berços) no térreo, além de cozinha e banheiro impróprio ao deficiente físico, não se adapta às necessidades educacionais (AMACH, 2008, p. 7).

Por fim, a AMACH denuncia que as obras têm implicado o remanejamento de muitas famílias, temporariamente, em casas chamadas "de passagem". Muitos residem nelas há anos. Por se situarem longe do bairro, nesses locais "as relações de vizinhança estão sendo destruídas" (AMACH, 2008, p. 10). Se a dimensão humana do espaço construído fosse levada em consideração, as próprias casas do IPAC localizadas no centro histórico (concedidas a terceiros que, muitas vezes, estão em situação de inadimplência) poderiam servir de casas de passagem.

A AMACH (1) denuncia que as unidades habitacionais destinadas às 103 famílias moradoras antigas do Pelourinho não tenham sido discutidas e pensadas com seus futuros usuários, (2) exige que os espaços coletivos do futuro bairro reformado sejam pensados coletivamente, (3) rejeita um equipamento (creche-escola) por não ter sido gerado pela comunidade e (4) lamenta as relações de vizinhança destruídas pelas casas de passagem (onde os futuros moradores aguardam o término da reforma) localizadas tão longe do centro. $\mathrm{O}$ que a AMACH reivindica, no fundo, é a lógica dos que detêm o poder de planejar (urbanistas) e construir (arquitetos), uma lógica segundo a qual o habitar não é concebido como um valor de uso, mas como valor de troca, precisamente porque se subordina às imposições dos rendimentos. Essa é a mesma lógica denunciada no Chile por Francisca Márquez:

Pensar a moradia somente desde o ângulo objetivo, isto é, em termos de valor de solo, paredes, tetos (...) é esquecer o básico: a necessidade de seus habitantes de ser considerados como responsáveis do que são e do que querem chegar a ser; como sujeitos capazes de escolher e optar pela sua própria história (...). Tratar a casa como um mero bem de capital e sua compra como uma estratégia econômica no sentido restrito do termo, fazendo abstração da trajetória percorrida por aqueles que a habitarão, é simplesmente despojá-la de todas suas propriedades históricas e simbólicas (MÁRQUEZ, 2005, p. 180). 
NORUS - v4, n.6, jul - dez 2016.

Segundo Lefebvre, o urbano, a vida urbana, se baseia no valor de uso, que não se confunde com o valor de troca, que é a equivalência no mundo da mercadoria:

O mundo da mercadoria tem sua lógica imanente, a do dinheiro e do valor de troca generalizado sem limites. Uma tal forma, a da troca e a da equivalência, só exprime indiferença diante da forma urbana; ela reduz a simultaneidade e os encontros à forma dos trocadores, e o lugar de encontro ao lugar onde se conclui o contrato ou quase-contrato de troca equivalente: o reduz ao mercado. A sociedade urbana, conjunto de atos que se desenrolam no tempo, privilegiando um espaço (sítio, lugar) e por ele privilegiados, altamente significantes e significados, tem uma lógica diferente da lógica da mercadoria. É um outro mundo. O urbano se baseia no valor de uso. Não se pode evitar o conflito (LEFEBVRE, 1969, p. 79).

O valor de uso de um objeto (ou mercadoria) encontra-se na satisfação das necessidades que ele oferece, está em sua função de sustentação da vida. Torna-se valor de troca quando se transforma em meio de troca. O valor de uso de um produto é a própria obra; o valor de troca, a sua equivalência. Os lugares onde impera o valor de uso são os refúgios do valor de uso, considerados pelo autor como os "embriões de uma virtual predominância e de uma revalorização do uso" (LEFEBVRE, 1969, p. 12). Só nesses refúgios podem imperar a verdadeira fruição, a beleza, o encontro. Nos locais do valor de troca, isto é, os espaços comprados e vendidos, os lugares do consumo dos produtos, dos bens, dos lugares e dos signos, imperam apenas o lucro, o proveito, as exigências e coações do mercado (LEFEBVRE, 1969).

É o valor de uso privilegiado pelo morador que nos ajuda a entender por que muitos invasores se negam a abandonar seus chamados barracos para morar em bairros distantes: a facilidade de transporte e proximidade do trabalho, a recusa da alta densidade populacional, mas, principalmente, a vizinhança conhecida, tornam-se mais importantes do que os valores materiais da infraestrutura urbana (ruas retilíneas, meios fios, escoamento pluvial, iluminação pública) (OLIVIERI, 1999, p. 68). É o valor de uso que explica também por que mais de 65\% das famílias que moram nos conjuntos habitacionais construídos pelo Estado chileno querem sair deles. Alfredo Rodríguez e Ana Sugranyes (2005) realizaram um estudo em parte das 500,000 moradias sociais construídas no Chile nos últimos 25 anos, que deram teto a $20 \%$ dos quinze milhões de habitantes do país. Uma quinta parte da população de Santiago mora nesses conjuntos habitacionais. Por que $2 / 3$ dos moradores desses conjuntos querem abandoná-los? A principal razão encontrada pelos autores é a percepção de insegurança e desconfiança que eles suscitam nos moradores, o que se reflete no abandono e deterioração dos espaços coletivos (SEGOVIA, 2005). Lefebvre diria que, neles, o habitar foi reduzido ao habitat:

E pode-se dizer que o "pensamento urbanístico" dos grandes conjuntos literalmente se encarnou na cidade e no urbano a fim de extirpá-los. Toda a realidade urbana 
perceptível (legível) desapareceu: ruas, praças, monumentos, espaços para encontros. Nem mesmo o bar, o café (o bistrot) deixou de suscitar o ressentimento dos "conjuntistas", o seu gosto pelo ascetismo, sua redução do habitar para o habitat (LEFEBVRE, 1969, p. 24).

Ao contrário dos assentamentos ilegais, nos quais o território é percebido coletivamente e os projetos partilhados possibilitaram a cooperação e, esta, por sua vez, a construção de uma identidade coletiva, os conjuntos habitacionais colocam lado a lado famílias que, de um dia para o outro, veem-se compelidas a morar junto umas das outras. Seguindo a perversa lógica do valor de troca, as unidades habitacionais destes conjuntos são muito pequenas e geram, em seguida, a falta de privacidade. Os espaços pequenos não foram pensados para ampliações e, assim, toda adequação da unidade supõe necessariamente a transgressão do espaço comum.

Todavia, o maior problema apontado pelos moradores é a ausência de vida social, de coletividade e vizinhança: "Para aqueles habitantes que provêm de acampamentos e que trazem uma história de participação e pobreza, não é a estreiteza de suas moradias o que mais lhes incomoda. É a ausência de gestos de solidariedade e de uma vida comunitária que eles mais sentem falta" (MÁRQUEZ, 2005, p. 171). À mesma conclusão chegou o trabalho de Nelson dos Santos (1981) ao analisar o conjunto habitacional Selva de Pedra, no Rio de Janeiro, na década de 1970. Nele, o convívio era visto como conflituoso e havia uma clara ausência de integração reconhecida pelos próprios moradores. Além das pessoas não se conhecerem, os conjuntos foram pensados para que estas continuem sem se conhecer: não há espaços e pessoas mediadoras que permitam e propiciem relações e negociações face a face; em vez delas, implementam-se mecanismos impessoais tais como regulamentos, regras, notificações e síndicos.

Chegamos assim à relação entre habitar, valor de uso e direito à cidade. Habitar é criar, é produzir mediante apropriações do espaço (e do tempo), mediante relações. Essas relações são colocadas em primeiro plano, tendo, desta forma, o valor de uso um predomínio sobre o valor de troca. Por sua vez, a prioridade do valor de uso está no centro do que Lefebvre chamou de direito à cidade:

$\mathrm{O}$ direito à cidade não pode ser concebido como um simples direito de visita ou de retorno às cidades tradicionais. Só pode ser formulado como direito à vida urbana, transformada, renovada. Pouco importa que o tecido urbano encerre em si o campo e aquilo que sobrevive da vida camponesa conquanto que "o urbano", lugar de encontro, prioridade do valor de uso, inscrição no espaço de um tempo promovido à posição de supremo bem entre os bens, encontre sua base morfológica, sua realização prático-sensível (LEFEBVRE, 1969, p. 108). 
É precisamente esse valor de uso que a AMACH reivindica nas quatro denúncias que aqui trouxemos. E essa reivindicação é tal porque a sua é uma lógica de um nível da realidade, a dos usuários, que é oposta à lógica do nível geral. Lefebvre distinguia níveis na realidade: um nível geral, o do poder, do Estado; um nível específico, o das relações imediatas, pessoais e interpessoais; e o nível intermediário, que é o da cidade. Lefebvre denuncia como o pensamento sociológico e a estratégia política omitem o nível específico, centrando-se apenas no nível geral:

Tendem a pular do nível do habitat e do habitar (nível ecológico, o da moradia, do imóvel, da vizinhança e, por conseguinte, domínio do arquiteto) para o nível geral (escala da disposição do território, da produção industrial planificada, da urbanização global), passando por cima da cidade e do urbano. Põe-se a mediação entre parênteses; omite-se o nível específico (LEFEBVRE, 1969, p. 71).

O usuário é simplesmente negado por eles, se “chega-se a evocá-lo ou invocá-lo, raramente chega-se a convocá-lo" (2000: 171). Se o nível do usuário é omitido, vimos, é porque ele representa o uso e não a troca.

Finalmente, Lefebvre pode ser trazido para o Pelourinho com mais uma de suas ideias, a de centralidade lúdica. É fundamental que a $\mathrm{AMACH}$ insista em seu projeto de quadra poliesportiva, pois este tipo de centralidade, de reunião, de encontro, é o avesso da troca:

Donde tirar o princípio da reunião e seu conteúdo? Do lúdico. O termo deve ser tomado aqui na sua acepção mais ampla e no seu sentido mais "profundo". O esporte é lúdico, o teatro também, de modo mais ativo e mais participante que o cinema. As brincadeiras das crianças não devem ser desprezadas, nem as dos adolescentes. Parques de diversão, jogos coletivos de todas as espécies persistem nos interstícios da sociedade de consumo dirigida, nos buracos da sociedade séria que se pretende estruturada e sistemática, que se pretende tecnicista (LEFEBVRE, 1969, p. 121).

Lefebvre incitava a não se contentar com centralidades passadas (o recinto sagrado, a ágora, o fórum, o centro de consumo - "lugar de consumo e consumo do lugar" -, o centro de decisão), mas imaginar novos espaços de invenção lúdica, espaços lúdicos, espaços qualitativos (e não quantificados, regulados, esquizofrênicos), ligados aos tempos e ritmos sociais. Neles, o valor supremo deveria se tornar o jogo, o imprevisto: "ou é um 'teatro espontâneo’ ou não é nada" (1969, p. 123):

O direito à cidade se manifesta como forma superior dos direitos: direito à liberdade, à individualização na socialização, ao habitat e ao habitar. $\mathrm{O}$ direito à obra (à atividade participante) e direito à apropriação (bem distinto de direito à propriedade) estão implicados no direito à cidade (LEFEBVRE, 1969, p. 124).

Nos dias atuais, David Harvey mantém a convicção de Lefebvre: o direito à cidade é um dos direitos mais importantes e, no entanto, um dos mais esquecidos. "A liberdade de nos fazer e nos refazer ao construir nossas cidades é, a meu ver, um dos direitos humanos mais 


\title{
A rebelião do vivido: Henri Lefebvre no centro de Salvador.
}

preciosos, mas também um dos mais negligenciados" (HARVEY, 2011, p. 8). A luta da AMACH continua.

\section{Os buracos do possível na avenida sete de setembro}

Na visão de Lefebvre (2002), a sociedade e o seu tempo encontravam-se numa transição, entre a sociedade industrial e a sociedade urbana. Vivia-se um ponto crítico ou zona crítica que consistia nas formas, funções e estruturas urbanas vendo-se transformadas pela explosão da cidade antiga e pela urbanização generalizada:

\begin{abstract}
Nesse movimento, a realidade urbana, ao mesmo tempo amplificada e estilhaçada, perde os traços que a época anterior lhe atribuía: de totalidade orgânica, sentido de pertencer, imagem enaltecedora, espaço demarcado e dominado pelos esplendores monumentais. Ela se povoa com os signos do urbano na dissolução da urbanidade; torna-se estipulação, ordem, repressão, inscrição por sinais, códigos sumários de circulação (LEFEBVRE, 2002, p. 26).
\end{abstract}

Assim, a realidade urbana tomou a forma de crise: crise da cidade e das instituições municipais (pois o Estado se apoderou das funções da sociedade urbana). A crise da cidade gerava, também, a crise do urbano, o qual,

\begin{abstract}
corroído, roído, perdeu os traços e as características da obra, da apropriação. Apenas as coações se projetam sobre a prática, num estado de deslocação permanente. Do lado da habitação, a decupagem e a disposição da vida quotidiana, o uso maciço do automóvel (meio de transporte "privado"), a mobilidade (aliás, freada e insuficiente), a influência dos mass-media separam do lugar e do território os indivíduos e os grupos (famílias, corpos organizados). A vizinhança se esfuma, o bairro se esboroa; as pessoas (os "habitantes") se deslocam num espaço que tende para a isotopia geométrica, cheia de ordens e de signos, onde as diferenças qualitativas dos lugares e instantes não têm mais importância (...) pobreza da vida quotidiana a partir do momento em que nada tomou o lugar dos símbolos, das apropriações, dos estilos, dos monumentos, dos tempos e ritmos, dos espaços qualificados e diferentes da cidade tradicional (LEFEBVRE, 1969, p. 75).
\end{abstract}

No entanto, ao mesmo tempo em que afirmava que a cidade deixava de ser cidade, que a não-cidade ou a anti-cidade conquistavam a cidade, a faziam explodir e a estendiam, levando à urbanização da sociedade, ao tecido urbano (LEFEBVRE, 2002), ele sustentava que $o$ urbano persistia no estado de embrião, de virtualidade (LEFEBVRE, 1969). Como $o$ urbano podia sobreviver na anti-cidade? Segundo Lefebvre, isso se dava porque a realidade urbana era produzida por duas forças: de um lado, os processos globais (econômicos, sociais, políticos) que modelaram o espaço urbano e a cidade, generalizando as trocas comerciais e a industrialização; de outro, a ação criadora, a apropriação, inventando, esculpindo o espaço, atribuindo ritmos, transformando a vida quotidiana (LEFEBVRE, 1969).

A cidade morria, mas o urbano permanecia vivo. Lefebvre entendida por cidade uma realidade presente, imediata, um dado prático-sensível, arquitetônico, um objeto definido e 
NORUS - v4, n.6, jul - dez 2016.

definitivo; já o urbano (ou vida urbana) não era uma realidade acabada, era o possível, as relações a serem concebidas, construídas ou reconstruídas pelo pensamento:

O "urbano" não pode ser definido nem como apegado a uma morfologia material (na prática, no prático-sensível) nem como algo que pode se separar dela. Não é uma essência a-temporal, nem um sistema entre os sistemas ou acima dos outros sistemas. É uma forma mental e social, a forma da simultaneidade, da reunião, da convergência, do encontro (ou antes, dos encontros). É uma qualidade que nasce de quantidades (espaços, objetos, produtos). É uma diferença ou, sobretudo, um conjunto de diferenças (LEFEBVRE, 1969, p. 78).

Para Lefebvre, a vida urbana tem suas necessidades, que denominou de necessidades da vida urbana: lugares qualificados, lugares de simultaneidade, de encontro, de troca pelo valor de uso e não pelo lucro (LEFEBVRE, 1969), pois ela "pressupõe encontros, confrontos das diferenças, conhecimentos e reconhecimentos recíprocos (inclusive no confronto ideológico e político) dos modos de viver, dos 'padrões' que coexistem na Cidade” (ídem, p. 20). É importante salientar que o conceito de vida urbana (em singular) representava, na prática, várias formas de vida urbana:

[não] negligenciar as singularidades da vida urbana, os modos de viver da cidade, o habitar propriamente dito. Donde uma outra definição, pela pluralidade, pela coexistência e simultaneidade no urbano de padrões, de maneiras de viver a vida urbana (o pavilhão, o grande conjunto, a copropriedade, a locação, a vida quotidiana e suas modalidades entre os intelectuais, os artesãos, os comerciantes, os operários etc.) (LEFEBVRE, 1969, p. 57).

Segundo Lefebvre, numa cidade em crise, devido ao período de transição, a vida urbana necessariamente tinha que se impor, se voltar contra, se desviar, usar a astúcia:

Esta vida urbana tenta voltar as mensagens contra elas mesmas, as ordens, as coações vindas do alto. Tenta apropriar-se do tempo e do espaço, frustrando as dominações, desviando-se de seus objetivos, usando de astúcia. Ela intervém, também, mais ou menos, ao nível da cidade e do modo de habitar. O urbano é, assim, mais ou menos, a obra dos citadinos em lugar de se impor a eles como um sistema: como um livro já acabado (LEFEBVRE, 1969, p. 64).

Mas quem são as pessoas que fazem e têm vida urbana? Para Lefebvre, tal pergunta não tem resposta certa, fechada, só pode ser respondida pelas pesquisas empíricas: “Os habitantes (quais? Cabe às pesquisas e aos pesquisadores encontrá-los!) reconstituem centros, utilizam certos locais a fim de restituir, ainda que irrisoriamente, os encontros" (LEFEBVRE, 1969, p. 76).

Façamos outras perguntas igualmente fundamentais: onde se faz esta vida urbana? Qual a prática que faz esta vida urbana? A prática é a da apropriação. Diante da passividade dos espaços absolutos, espaços abstratos da sociedade em transição, Lefebvre opõe a prática social nova, a da sociedade urbana, que é a "prática da apropriação, pelo ser humano, do tempo e do espaço, modalidade superior de liberdade" (LEFEBVRE, 2000, p. 131). A 


\section{A rebelião do vivido: Henri Lefebvre no centro de Salvador.}

apropriação é um conceito-chave para entender como, no meio de uma anti-cidade, a vida urbana pode não só sobreviver como se intensificar. Apropriar-se de espaços (e tempos) é não aceitar o imposto, é metamorfosear o imposto em obra (LEFEBVRE, 1969), é a capacidade de transformar a realidade, logo, é a apropriação que restitui à cidade o seu sentido de obra e não apenas produto.

Onde acontecem as apropriações que mantêm viva a vida urbana? De acordo com Lefebvre, o urbano, isto é, a vida urbana, "se mantém nas fissuras da ordem planificada e programada" (LEFEBVRE, p. 1969), nos buracos, nos vazios, considerados pelo autor como lugares do possível:

Entre os subsistemas e as estruturas consolidadas por diversos meios (coação, terror, persuasão ideológica) existem buracos, às vezes, abismos. Esses vazios não provêm do acaso. São também os lugares do possível. Contém os elementos deste possível, elementos flutuantes ou dispersos, mas não a força capaz de os reunir. Mais ainda: as ações estruturantes e o poder do vazio social tendem a impedir a ação e a simples presença de semelhante força. As instâncias do possível só podem ser realizadas no decorrer de uma metamorfose radical (LEFEBVRE, 1969, p. 106).

As ideias e conceitos de Lefebvre expostos até aqui nos ajudam a interpretar alguns personagens, lugares e práticas que encontramos na Avenida Sete de Setembro, no centro de Salvador. Na verdade, trata-se da Rua do Forte, que une o Campo Grande à Avenida Sete, uma rua de prédios principalmente residenciais que, em seus níveis térreos, abrigam diversos tipos de espaços comerciais. Nessa rua localizam-se quatro becos. Neles, instalam-se, todo dia, por volta das 7,30h, ambulantes de gêneros alimentícios: uma vendedora de beiju, com uma clientela matutina fiel; catadores de feijão verde; vendedores de legumes; de castanha e camarão seco; um vendedor de queijo e goiabada e um vendedor de temperos.

Um dos vendedores de castanha e camarão seco é Gerson, um senhor alegre e conversador, viúvo, que passa dos 60 anos, porém, muito bem conservado, magro e torrado pelo sol. Ele mora no Lobato (“pertinho, faço em 20 minutos!"), veio de interior da Bahia na década de 1950 e trabalha no local há mais de 20 anos. Seu sonho é ter um barco (como gosta de desenhar, desenhou um para mim). Segundo ele, a venda já foi bem melhor na área, quando a Prefeitura não impedia os ambulantes de colocarem seus balaios na rua e o pessoal da Gamboa de Baixo ganhava um dinheirinho vendendo os peixes que eles mesmos pescavam. Atualmente, há uma vigilância constante da comercialização de produtos alimentícios no trecho, obrigando os ambulantes a usar a tática de oferecerem seus produtos dentro dos becos. 
NORUS - v4, n.6, jul - dez 2016.

Eles guardam seus produtos em depósitos localizados nos próprios becos que compõem o trecho. Como são conhecidos pelos moradores devido ao tempo em que trabalham no local, os moradores ou donos dos estabelecimentos comerciais da área lhes permitem guardar seus balaios e vender suas mercadorias nas vielas. Gerson guarda seus produtos num pequeno depósito localizado na entrada de um dos becos que serve de acesso a uma série de moradias. Mas a condição é que o comércio seja pequeno: “As véia não deixam colocar meus balaios, só essa pequena quantia, ai de mim se botar um balaio, me denunciam!", confessou.

Vendedores como Gerson se apropriam dos espaços centrais normatizados por ideias higienistas baseadas em certos conceitos do que é moderno e aceitável e do que não o é. Apropriam-se, isto é, tornam seu um espaço que não é ou não deveria sê-lo; usam o espaço para a sua sobrevivência, para suprir suas necessidades vitais; com astúcia, negociam esta apropriação, na medida do possível; como ceramistas, vão moldando esse espaço em função dos usos que lhe conferem. Os espaços onde estas apropriações acontecem, e que Lefebvre chama de vazios ou buracos, são, neste caso, os becos, espaços dissimulados, fronteiriços, entre a casa e a rua. São os lugares do possível, onde a virtualidade do urbano se concretiza.

$\mathrm{O}$ personagem desta façanha é Gerson. Ator que se rebela pelo vivido e, com isso, produz vida urbana. Uma que gera relações, que provoca encontros, simultaneidade. Assim o evidenciamos num trabalho mais descritivo sobre os diversos espaços da Avenida Sete:

\footnotetext{
Certa vez, acompanhamos Gerson (o vendedor de camarão seco e castanhas) durante uma hora e meia. Nesse tempo, ele troca cumprimentos com mais de quinze pessoas, vendedoras e vendedores da área, moradores, funcionários: "E aí Gerson?", diz um, passando; "Cadê os quiabos?", diz outra pessoa, parando um pouco; "e aí, Professor?", diz, por sua vez, Gerson, para um senhor em movimento. Ele nos explica quem são cada uma dessas pessoas: "Essa é uma peça" (forma de se referir a um morador homossexual, bancário, aposentado, que lhe deixa sacolas de supermercado para ele usar em suas vendas), "essa é barona" (senhora que mora no Politeama), "esse é um professor aposentado, freguês, chorão, mas gente boa". Conhece todo mundo (CARVALHO FILHO; MONTOYA URIARTE, 2012b).
}

Se bem Lefebvre não tenha dito quem são os atores a fazer a vida urbana (vão os pesquisadores à rua pesquisar!), ele ofereceu um perfil geral. A luta pela vida urbana é obsessão dos não-integrados, dos pobres, dos excluídos. Serão eles a lutar pela simultaneidade, integração, junção:

O urbano é a obsessão daqueles que vivem na carência, na pobreza, na frustração dos possíveis que permanecem como sendo apenas possíveis. Assim, a integração e a participação são a obsessão dos não-participantes, dos não-integrados, daqueles que sobrevivem entre os fragmentos da sociedade possível e das ruínas do passado: excluídos da cidade, às portas do "urbano" (LEFEBVRE, 1969, p. 93). 


\section{A rebelião do vivido: Henri Lefebvre no centro de Salvador.}

Numa análise muito semelhante, Milton Santos escreveu sobre as "contraracionalidades", esses usos do espaço a partir de outras racionalidades (que não do valor de troca) desenvolvidas pelos excluídos:

Essas contra-racionalidades se localizam, de um ponto de vista social, entre os pobres. Os migrantes, os excluídos, as minorias; de um ponto de vista econômico, entre as atividades marginais, tradicional ou recentemente marginalizadas; e, de um ponto de vista geográfico, nas áreas menos modernas e mais "opacas", tornadas irracionais para usos hegemônicos. Todas essas situações se definem pela sua incapacidade de subordinação completa às racionalidades dominantes, já que não dispõem dos meios para ter acesso à modernidade material contemporânea. Essa experiência da escassez é a base de uma adaptação criadora à realidade existente (SANTOS, 1996, p. 246).

Mais recentemente, Harvey (2011) levou adiante esta ideia. Segundo ele, não será o proletariado a fazer a revolução urbana, a exigir o direito à cidade. Será o que ele denomina de precariado:

O que chamamos de "precariado" tem suplantado o tradicional "proletariado". Se deve haver um movimento revolucionário hoje e neste lado do mundo (em oposição à China que se industrializa), é do lado da problemática do "precariado" desorganizado que devemos olhar. Como tais grupos díspares poderiam se autoorganizar para constituir uma força revolucionária, eis o problema político mor. $\mathrm{E}$ uma parte do problema consiste em compreender as origens e a natureza de seus gritos e suas reivindicações (HARVEY, 2011, p. 40).

Gerson sobrevive, literalmente, entre os fragmentos da sociedade: excluído da rua, impossibilitado de entrar no mundo da formalidade econômica. No beco, faz o possível acontecer: sobrevive, tece suas redes, conversa, vê o que resta da cidade e constrói a vida urbana de todos aqueles com quem ele se relaciona. Na Rua do Forte, os becos são os lugares do possivel.

\section{À guisa de conclusão: saindo dos campos cegos}

Lefebvre era um homem que acreditava na ideia de revolução. Em A revolução urbana definiu a mesma como o "conjunto das transformações que a sociedade contemporânea atravessa para passar do período em que predominam as questões de crescimento e de industrialização (...) ao período em que a problemática urbana prevalecerá decisivamente" (LEFEBVRE, 2002, p. 18). Acreditava ser a cidade o lugar da revolução e as questões urbanas os motivos desta: "as contradições não se situam mais entre a cidade e o campo. A contradição principal se desloca e se situa no interior do fenômeno urbano: entre a centralidade do poder e as outras formas de centralidade, entre o centro 'riqueza-poder' e as periferias, entre a integração e a segregação" (LEFEBVRE, 2002, p. 155). 
NORUS - v4, n.6, jul - dez 2016.

A revolução se faria na cidade e pela cidade e as transformações não viriam das saídas institucionais: "até nova ordem, a prática social encontra-se submetida aos políticos. Eles apoderam-se dela através das instituições e dos aparelhos (...). Eles se movimentam no interior de marcos institucionais e ideológicos, quando se trata, precisamente, de transpô-los" (LEFEBVRE, 2002, p. 131). Então, viriam de onde? Não do proletariado, mas dos trabalhadores urbanos, do urbano que resta, isto é, da vida urbana construída pelos excluídos mediante apropriações de espaços e tempos ou exigida pelos movimentos sociais urbanos, não industrializados ou operários. No entanto, Lefebvre admitia que não era fácil enxergar essa força, esses novos atores, essas novas fórmulas de luta. Em A revolução urbana, ele designava o seu momento atual como um estágio entre duas épocas, no meio, no corte, nas dobras delas. Entre elas, existiam campos cegos, na medida em que não conseguíamos enxergar:

\footnotetext{
Em que consiste tal cegueira? No fato de olharmos atentamente o campo novo - o urbano - vendo-o, porém, com os olhos, com os conceitos, formados pela prática e teoria da industrialização, com um pensamento analítico fragmentário e especializado no curso desse período industrial, logo, redutor da realidade em formação (LEFEBVRE, 2002, p. 38).
}

Para sair da cegueira, é preciso se despojar de velhos conceitos ou ideias fixas, e ver nas novas práticas, novos atores e novos lugares, embriões de uma nova realidade urbana. A luta não se reduz a um discurso articulado, a uma prática organizada, a um movimento centralizado. Lefebvre abriu um caminho ao nos lembrar que é preciso enxergar com novos olhos o campo novo que surge. Seguindo a trilha de Lefebvre, David Harvey (2012) nos incita hoje a nos perguntarmos quem está produzindo e reproduzindo a vida urbana. Este artigo trouxe Lefebvre, as queixas e reivindicações da $\mathrm{AMACH}$, e o espaço e as práticas de Gerson: uma pequena contribuição para o desafio aberto por Lefebvre e retomado por Harvey.

\section{Referências}

ASSOCIAÇÃO de Moradores e Amigos do Centro Histórico (AMACH). Dossiê. Salvador: 2008, 11p. (mimeo).

CARVALHO FILHO, Milton Julio de; MONTOYA URIARTE, Urpi. A Avenida Sete e seus transeuntes. In: CARVALHO FILHO, Milton Julio de; MONTOYA URIARTE, Urpi. (org.). Panoramas Urbanos: usar, viver e construir Salvador. Salvador: Edufba, 2012a. (no prelo).

Transeuntes e usos da Avenida Sete. In: CARVALHO FILHO, Milton Julio de; MONTOYA URIARTE, Urpi. Panoramas Urbanos: usar, viver e construir Salvador. Salvador: Edufba, 2012b. (no prelo). 
DEULCEUX, Sandrine; HESS, Remi. Henry Lefebvre. Vie, ouevres, concepts. Paris: Ellipses, 2009.

HARVEY, David. As cidades rebeldes de David Harvey [Online], 2012. Disponível em www.outraspalavras.net/2012/07/13/as-cidades-rebeldes-de-david-harvey; Acesso em: 20/07/2012.

Le capitalisme contre le droit à la ville. Néoliberalisme, urbanisation, résistances. Paris: Amsterdam, 2011.

Espaços de esperança. São Paulo: Loyola, 2004.

KHOTARI, Miloon. Observações preliminares do relator especial das Nações Unidas para a moradia adequada, Sr. Miloon Khotari, sobre sua missão ao Brasil (30 mai.-11 jun. 2004). Coletiva de Imprensa: Salvador, 11 jun. 2004, 10p. (mimeo).

LEFEBVRE, Henri. A revolução urbana. Belo Horizonte: UFMG, 2002 [1970].

La production de l'espace. 4. ed. Paris: Anthropos, 2000 [1974].

O direito à cidade. São Paulo: Documentos, 1969 [1968].

LETHIERRY, Hugues. Penser avec Henri Lefebvre. Sauver la vie et la ville? Lyon: Chronique Sociale, 2009.

MÁRQUEZ, Francisca. De lo material y lo simbólico en la vivienda social. In: RODRÍGUEZ, Alfredo; SUGRANYES, Ana (ed.). Los con techo. Un desafío para la política de vivienda social. Santiago: Sur, 2005.

MONTOYA URIARTE, Urpi. Pobreza e cultura. A luta dos pobres para permanecer morando no Centro Histórico de Salvador. Cadernos PPG-AU, Número especial sobre Patrimônio, Salvador, v. 10, n. 1, 2012a.

. O lugar da história no consumo do chamado patrimônio histórico. Interseções: Revista de Estudos Interdisciplinares. Rio de Janeiro, v. 14, n. 1, 2012 b.

. Por trás das fachadas coloridas. Etnografias nos "novos" Bairro do Recife (Pernambuco) e Pelourinho (Bahia). Pontourbe, São Paulo, v. 4, n. 7, 2010.

Intervenções recentes em centros históricos: as políticas de "recuperação" dos centros históricos de Salvador, Lima e Quito. Cadernos do CEAS, Salvador, n. 208, 2003.

OLIVIERI, Alberto Freire de Carvalho. O desenho da mudança social na arquitetura de “invasão". Salvador: Edufba, 1999.

RODRÍGUEZ, Alfredo; SUGRANYES, Ana (ed.). Los con techo. Un desafío para la política de vivienda social. Santiago: Sur, 2005.

SANTOS, Milton. Os espaços da racionalidade. In: SANTOS, Milton. A natureza do espaço. Técnica e tempo. Razão e emoção. São Paulo: Hucitec, 1996. 
NORUS - v4, n.6, jul - dez 2016.

SANTOS, Nelson Ferreira dos et al. Quando a rua vira casa. A apropriação de espaços de uso coletivo em um centro de bairro. 2. ed. revisada e atualizada. Rio de Janeiro: IBAM/FINEP, 1981.

SEGOVIA, Olga. Habitar en conjuntos de vivienda social: cómo construir identidad, confianza y participación social? In: RODRÍGUEZ, Alfredo; SUGRANYES, Ana (ed.). Los con techo. Un desafío para la política de vivienda social. Santiago: Sur, 2005. 